\title{
Review of Anna Alexandrova's A Philosophy For the Science of Well-Being. New York: Oxford University Press, 2017, 196 pp.
}

\author{
MATS INGELSTRÖM \\ University of Stockholm
}

In A Philosophy for the Science of Well-Being, Anna Alexandrova urges us to revise the way we theorise about well-being. The traditional approach in philosophy is to search for the universal and most general theory of what well-being is. Alexandrova argues that this approach, to a large extent, is irrelevant and unhelpful. For most people concerned with wellbeing-either as policy makers trying to decide what to do, or as scientists trying to understand and measure well-being in more specific groups-the traditional approach won't do. Instead, she argues, we need to theorise about well-being in new ways.

This is a wide-ranging book with a refreshingly ambitious agenda. In it, Alexandrova consolidates the positions and arguments that she has developed and published over the recent years. The book concerns the role scientists and their scientific inquiries can and should have in our pursuit of understanding, identifying and measuring human well-being. Alexandrova wants to give an answer to "how science should define well-being, how it should measure it, and the role of philosophy in all this" $(x v)$. In doing so, she explains and takes seriously recent developments in both the philosophical and the scientific field. She discusses issues ranging from theory building and concept formation, to validation and measurement. As far as I am aware, the book is unique in this way. I highly recommend anyone working in this area to read it.

The book starts with a helpful and pertinent introduction. We then get the two main parts: Tools for Philosophy and Tools for Science. Each part consists of three chapters. In two brief appendices, readers unfamiliar with the landscape are offered quick summaries of the status in contemporary work on well-being in philosophy and science. As a reader of paper books, I also appreciated the useful and detailed index.

A Philosophy for the Science of Well-Being engages from page one. Rather than making some sweeping general remarks, this review will focus on giving a rather detailed discussion of part one. Part one can be 
read as a unified proposal, and it is here Alexandrova advances her revisionist account of how philosophers should theorise about wellbeing. Part two is also interesting and contains an important collection of ideas concerning the limits of scientific inquiry regarding well-being, but these ideas are less unified and each chapter in part two would require its own detailed discussion.

In part one, Alexandrova challenges traditional philosophical views on what well-being is and how it should be investigated. Unimpressed with the traditional approach, where philosophers attempt to formulate what constitutes and grounds well-being in its most general sense, Alexandrova instead formulates and defends a position she labels WellBeing Variantism.

Variantism involves two claims: Concept diversity and Theory diversity. Concept diversity tells us that "'well-being' (and its cognates) can invoke either general or contextual concepts of well-being depending on context" (43). The context Alexandrova refers to is that of the evaluator who invokes the well-being concept, for example a scientist who seeks to characterise a well-being construct. The other part of Variantism, Theory diversity, makes the meta-substantive claim that "[n]o single substantive theory specifies the realisers of every concept of well-being" (43).

Alexandrova takes the implication of her Variantism to run deep. Denying the traditional invariantist position is not merely of scholarly curiosity. Alexandrova wants to significantly broaden the scope of philosophical well-being theory. If Variantism is right, the traditional search for a single unified substantive theory of well-being, exemplified in the debates between versions of the "big three" (hedonism, desire theories and objective list theories, see, for instance, Crisp 2017), at best addresses merely one of many relevant notions of well-being. So, should we believe in Variantism?

Chapter one defends Concept diversity. Let us look closer at what it says. First, it states that there is more than one kind of well-being evaluation. Call this part Diversity. Secondly, it states that the diversity depends on the context of the evaluator. Call this Dependence. Diversity indeed seems plausible. I am less convinced by Dependence, especially if it is understood in a deeper, fundamental sense.

Diversity gains support from observations of how 'well-being' is used. Early in chapter one, Alexandrova shows that the term 'well-being' is often used in a merely some-things-considered sense, in contrast to 
the general all-things-considered sense which philosophers traditionally assume. In some contexts, such as that of a sincere conversation between close friends, well-being invokes one type of evaluation. In other contexts, such as that of a policy researcher, it might invoke other evaluations. Alexandrova provides some concrete and convincing examples to support this observation.

Perhaps some would want to disqualify using 'well-being' for anything but general all-things-considered evaluations. If anyone holds that view, Alexandrova makes a convincing case against them (she labels this position Circumscription, 8-10). She argues forcefully that philosophers should take the linguistic practice of non-philosophers seriously. There seems to be no good justification, she emphasizes, for the claim that scientists and others who use 'well-being' in merely somethings-considered senses are not really talking about well-being. Instead, we should accept that well-being-talk can invoke either general or partial evaluations. Furthermore, it seems plausible that which type of evaluation we are interested in may change with the context of the inquiry.

Next, turn to the Dependence part of Concept diversity. It is a bit unclear how we should interpret this dependence. Inspired by recent discussions on contextualism with regards to knowledge, Alexandrova suggests and discusses two options that would make the concept of well-being in some way depend on context. According to the The Different Realisation view, the threshold for when someone counts as doing well depends on context. According to Contextualism, the content of the concept depends on context (see 10-14). But perhaps these two are not the only possible options?

Let me propose a different explanation of what is going on here. One could point out that the general all-things-considered evaluation philosophers normally have in mind is merely one, an important but very thin, precisification of our fuzzy pre-theoretical well-being concept. There are many other precisifications which are thicker in descriptive content and thus less general, such as "physical well-being for elderly", "student emotional well-being in elite universities" and "economic wellbeing of young parents". The fact that scientists invoke different such precisifications could be explained without making the concept dependent on context in a deeper sense. In different contexts, we often have different aims and problems we are trying to solve. Our aims and problems can call for different kinds of well-being evaluations, not 
because the context dictates the content or the threshold of the evaluation, but because the context makes different kinds of well-being evaluations more or less relevant (or salient). A general ambition within the sciences (as well as in ordinary talk) to be relevant would then explain the diversity. This would not, however, establish a deeper dependence between context and concept. If this explanation works, we could circumvent the Dependence part of Concept diversity, while leaving Diversity intact. As far as I can see, there would be no harm to the overall project of the book of doing so. When Alexandrova in her afterword sums up her position, she indeed leaves out the dependence claim: "My hypothesis is that the content of the concept of well-being, at least partly, varies with context." (153).

Chapter two focuses on defending Theory diversity, the second part of Variantism. Theory diversity denies that there is a single substantive theory of well-being that covers all situations in which we make wellbeing judgments. Rather, what constitutes well-being may vary with context. Alexandrova structures her argument in five premises: ${ }^{1}$

Premise 1: The philosophical toolbox of the sciences of well-being includes many, not only one, of the current theories of wellbeing.

Premise 2: Depending on the context, different contents of the toolbox play a role in different constructs of well-being.

Premise 3: Constructs of well-being, at least sometimes, specify the constituents, rather than mere causes or correlates, of wellbeing.

Premise 4: Constructs of well-being in the sciences, at least sometimes, do a good job picking out well-being in a given context.

Conclusion: So different states, as specified by different theories, constitute well-being in different contexts. (45-46)

There are some things that should be noted here. A minor observation is that one could, strictly speaking, accept the premises while denying the conclusion. An Invariantist could agree with each step, but simply claim that the only times both premise 3 and 4 hold, are when a well-being construct aligns with the single correct substantial well-being theory. This might not be the intended reading of the argument, but I fail to see an easy rewording that would close this

\footnotetext{
${ }^{1}$ The toolbox-view of scientific theories (Cartwright et al. 1995) holds that scientific theories should be understood as useful, yet incomplete, tools for constructing models that correctly represent the world (35-40).
} 
escape route for the Invariantist. That said, the argument might still provide some inductive reason for accepting Theory diversity.

How plausible are the premises? The first two premises gain much of their support from the way science is conducted. In the first half of chapter two, Alexandrova carefully argues that we should take the methodological variability we see in the various well-being sciences seriously. From the discussion in chapter one, we learned that different contexts prompt different kinds of evaluations. The kinds of questions a scientist seeks to answer and the resources she has available matter for how she will characterise and measure what she calls well-being. Alexandrova acknowledges that such different approaches could in principle be compatible with, and supported by, the existence of a single unified substantial well-being theory. However, since no theory to fill this function is currently available, she puts her bet on the pluralism running deep.

Alexandrova's reasoning here is persuasive. I find it difficult to disagree with her on this, especially if the toolbox of premise 1 is understood as giving support for constructs, rather than ultimately justifying them in the evaluative sense. A well-being theory could support a construct by pointing to important insights, such as that wellbeing is perspectival or that people tend to flourish by being virtuous. Different constructs of well-being might be relevant and helpful for differing contexts and types of evaluation. Therefore, even if two incompatible well-being theories cannot both justify (evaluatively) a well-being construct, they could both constitute support for it. Invariantists should accept this.

The Invariantist should instead question premise 3. Why should someone who does not already accept Variantism give credence to the claim that constructs used in the sciences sometimes pick out the constituents of well-being, unless they have scrutinized the constructs in question? In her discussion, Alexandrova acknowledges that constructs often are based on indicators rather than constituents, but she maintains that this need not always be the case. Sometimes, she claims, researchers consider themselves to be investigating the constituents of well-being. She argues that the burden of proof should therefore be on the Invariantist to show that they really are not. The Invariantist, however, could at this point hold their ground and insist that we have no reasons to blankly believe a well-being construct specifies constituents, and especially not to believe that it both specifies 
the constituents and gets it right (as premise 4 states), unless we carefully look into the specific construct.

Regardless of how the chips fall on Theory diversity, Alexandrova's discussion has at this point led us to an important insight. Scientific constructs of well-being should be justified by their epistemic merits in the contexts they are used. A general substantial well-being theory might be fairly silent on which of the competing constructs is best in a given context. To illustrate, consider Stated preferences, a well-being construct sometimes used in welfare economics (see, for instance, Benjamin et al. 2014). Such a construct could be supported by a desire satisfaction account of well-being, but not if we believe humans tend to be poor at gauging their own desires (which could be especially plausible if the account invokes idealised desires). At the same time, such a construct could also be supported by a hedonistic or objective list account of well-being, if we have reasons to believe humans tend to align their preferences with what benefits them.

Variantists and Invariantists alike should acknowledge that for most practical purposes, we need conceptions that combine the value-making features of substantial well-being theories with our knowledge of human beings and their needs, wants, and desires in different situations of life. It is a shortcoming of the traditional approach to only focus on abstract well-being theories. In chapter three, Alexandrova goes on to propose and exemplify an alternative to this traditional approach by laying out a theory of child well-being. Alexandrova calls this kind of theory a midlevel theory of well-being. A central feature of such theories is that wellbeing is predicated not on individuals, but on kinds. This is an interesting suggestion and I hope the book will mark the beginning of a research program where mid-level theories of well-being will be discussed and developed much further. Well-being scientists often investigate general tendencies that only hold in a specific kind of situation, rather than universal claims. Well-being predicated on kinds might therefore better characterise what they are attempting to measure. At the same time, the focus on mid-level theories should help us see the gap between scientific well-being measures and well-being as it figures in central normative debates concerning the good life, justice and moral value. We should be careful not to forget that it is the wellbeing of individuals that matters normatively. We care about beings, not about kinds of beings. 
In part two of the book, Alexandrova moves on to discuss questions that regard the scientific status of well-being science. In chapter four, she argues that well-being science must be value-laden, but that this is compatible with scientific standards of objectivity. Chapter five makes the case against critics of well-being measurability. Alexandrova discusses an objection she attributes to Hausman (2015), which is that well-being cannot be measured because people are too heterogenous. Even if we can measure some individual well-being components, we cannot know how much different components contribute to different people's well-being. Alexandrova accepts the objection in the case of general all-things-considered evaluations, but she argues that well-being predicated on kinds might still be measurable. Chapter six contains a careful and critical discussion of how well-being constructs are validated in psychometrics.

To wrap up, the overall theme of this book resonates with a development we have seen in other areas of philosophy. Universal aims are being questioned. In political philosophy, proponents of non-ideal theory question the old approach of searching for universal theories of justice. In philosophy of science, the old focus on universal general laws and explanations is being replaced by detailed discussions of less universal mechanisms and local law-like regularities. Alexandrova challenges the old focus on universal and general theories in philosophy of well-being, and argues that they should be replaced by a new focus on mid-level theories.

\section{REFERENCES}

Benjamin, Daniel J., Ori Heffetz, Miles S. Kimball, \& Nichole Szembrot. 2014. "Beyond Happiness and Satisfaction: Toward Well-Being Indices Based on Stated Preference." The American Economic Review 104 (9): 2698-2735.

Cartwright, Nancy, Towfic Shomar \& Mauricio Suárez. 1995. "The Tool Box of Science". Poznan Studies in the Philosophy of the Sciences and the Humanities 44: 137149.

Crisp, Roger. 2017. "Well-Being." In The Stanford Encyclopedia of Philosophy, edited by Edward N. Zalta. Retrieved from <https://plato.stanford.edu/entries/wellbeing/>.

Hausman, Daniel M. 2015. Valuing Health: Well-Being, Freedom, and Suffering. Oxford University Press.

Mats Ingelström is a final year $\mathrm{PhD}$ candidate at Stockholm University. He has written and lectured on well-being, measurement and political philosophy. His dissertation project investigates the policy relevance of subjective well-being science.

Contact e-mail: <mats.ingelstrom@philosophy.su.se> 